\title{
High-speed Electrical Discharge Machining with a 5-DOF Controlled Maglev Actuator
}

\author{
Xiaoyou ZHANG ${ }^{1}$, Tadahiko SHINSHI ${ }^{2}$, Akira SHIMOKOHBE ${ }^{3}$ \\ Yoshihito IMAI ${ }^{4}$, Hidetaka MIYAKE ${ }^{4}$ and Takayuki NAKAGAWA ${ }^{4}$ \\ ${ }^{1}$ Precision and Intelligence Laboratory, Tokyo Institute of Technology, Japan, zhang.x.ac@m.titech.ac.jp \\ ${ }^{2}$ Precision and Intelligence Laboratory, Tokyo Institute of Technology, Japan, shinshi.t.ab@m.titech.ac.jp \\ ${ }^{3}$ Precision and Intelligence Laboratory, Tokyo Institute of Technology, Japan \\ ${ }^{4}$ Advanced Technology R\&D Center, Mitsubishi Electric Corporation, Japan
}

\begin{abstract}
:
The object of this study is to realize high-speed electrical discharge machining (EDM) using a wide-bandwidth, high-precision, millimeter-stroke, 5-DOF controlled maglev local actuator. In this paper, we report on the EDM of small holes using this actuator, and discuss the relationships between machining speed, the bandwidth of the actuator and the control gain of the EDM system. The experimental results show that the machining speed using the actuator was improved as the bandwidth of the actuator and control gain of the EDM system increased.
\end{abstract}

\section{KEYWORDS: ELECTRICAL DISCHARGE MACHINING, MAGLEV LOCAL ACTUATOR,} MACHINING SPEED

\section{INTRODUCTION}

Electrical discharge machining (EDM) is a widely-used machining technique, for machining complex shapes or hard material parts [1-3]. However, the speed and accuracy of conventional EDM are limited by the probability and efficiency of the electrical discharge. To improve the machining speed and accuracy, a combination of a conventional electrical discharge machine and a high-speed, high-precision local actuator, which can speedily re-position the electrode to obtain a stable electrical discharge, was proposed, as shown in Fig. 1 [4-6]. For this actuator, a positioning stroke of a few millimeters for rapid retraction of the electrode in at least one direction of motion (for example, the thrust direction) is also necessary, in order to remove debris from around the electrode when holes with high aspect ratio are machined.

To realize high speed positioning of the electrode with a stroke of a few millimeters, the authors have developed a

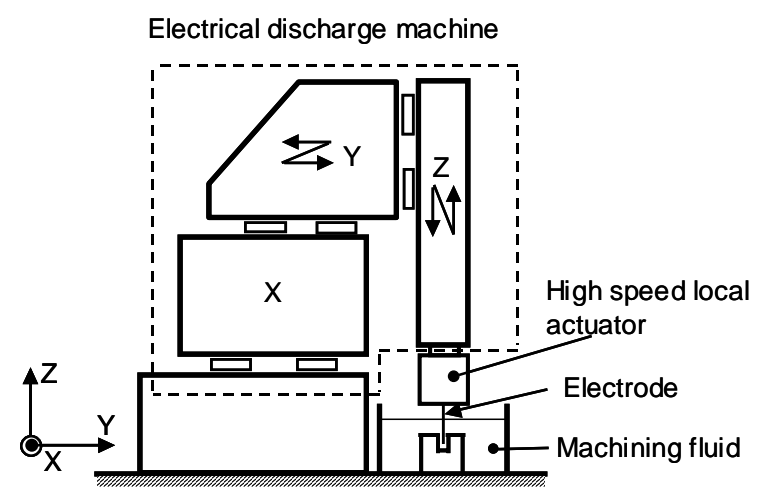

(a) Schematic drawing of the electrical discharge machine with a local actuator maglev local actuator for positioning the electrode in 5 -DOF $[7,8]$. The actuator is sufficiently compact to be attached to conventional electrical discharge machines. It not only has a wide-bandwidth and high-precision in 5-DOF, but also a stroke of a few millimeters in the thrust direction in order that periodic rapid retraction of the electrode can be realized.

In this paper, we report on the EDM of small holes using this actuator focusing on the relationships between machining speed, the bandwidth of the actuator and the control gain of the EDM system. Furthermore, using the multi-DOF positioning function of the actuator, the possibility of adjusting the diameter of the hole is also examined.

\section{5-DOF CONTROLLED MAGLEV LOCAL ACTUATOR}

Fig. 1(b) shows the proposed 5-DOF controlled maglev local actuator. It primarily consists of a voice coil

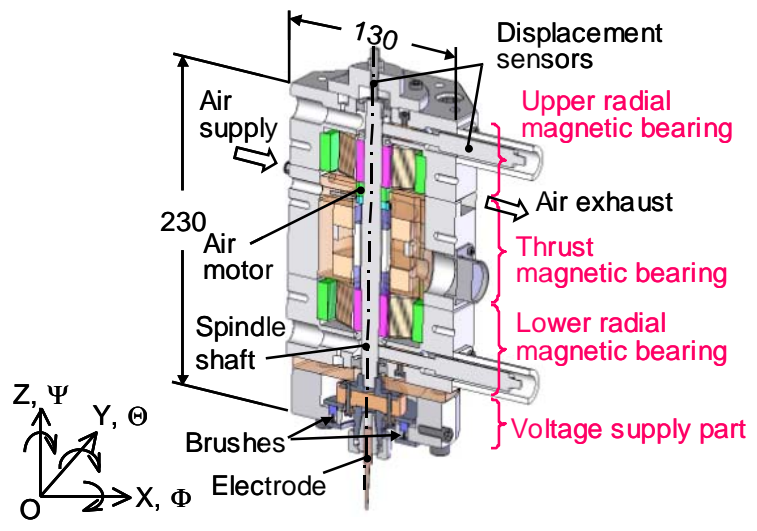

(b) A proposed maglev local actuator

Fig. 1. Electrical discharge machine with a local actuator 
motor type of thrust magnetic bearing with a positioning stroke of a few millimeters, a pair of reluctance type radial magnetic bearings, an air motor and brushes for the voltage supply. Using the thrust and radial magnetic bearings, the spindle shaft can be levitated and positioned in 5-DOF (X, Y, Z, $\Theta$ and $\Phi$ ), while, using the air motor, the spindle shaft can be rotated around the $\mathrm{Z}$-axis without generating heat. The voltage for EDM is applied to the electrode via four brushes.

The length of the actuator without an electrode and its attachment is $230 \mathrm{~mm}$ and the width is $130 \mathrm{~mm}$. The total mass is about $26 \mathrm{Kg}$. The actuator has submicron and micro-radian positioning resolution and a bandwidth greater than $100 \mathrm{~Hz}$ in the 5-DOF directions. The positioning stroke is $2 \mathrm{~mm}$ in the $\mathrm{Z}$ direction, $200 \mu \mathrm{m}$ in the $\mathrm{X}$ and $\mathrm{Y}$ directions, and $2 \mathrm{mrad}$ in the $\Theta$ and $\Phi$ directions.

\section{ELECTRICAL DISCHARGE MACHINING SYSTEM USING THE MAGLEV LOCAL ACTUATOR}

In order to improve the machining speed of EDM, the actuator was attached to an electrical discharge machine (EA12E, Mitsubishi Electric Corp.). In the experiments, the electrical discharge machine was used only to move the electrode to the initial position and to supply the voltage to the electrode. The electrode was controlled solely by the actuator in order to maintain it at a suitable distance from the workpiece.

A cylindrical shaped copper electrode with a diameter of $1 \mathrm{~mm}$ was used and was not rotated or retracted during EDM. The machining fluid was EDF-K (Nippon Oil Corp.), and the workpiece was age-hardened mold steel, which has a hardness of 40 HRc (NAK80, Daido Steel Corp., Ltd.). The discharge circuit was an RC circuit with a resistance and capacitance of $1.1 \mathrm{~K} \Omega$ and $0.01 \mu \mathrm{F}$, respectively, and the open-circuit voltage was $120 \mathrm{~V}$. These were the conditions used for finish machining.

To maintain a stable electrical discharge, the voltage between the electrode and the workpiece was kept at a constant value by rapidly changing the distance between the electrode and the workpiece. A block diagram of the EDM system is shown in Fig. 2. The gap voltage, $V$, is amplified and averaged by a low-pass filter, and the average voltage, $V_{f b}$, is used as a feedback signal. The gain of the amplifier is -0.03 and the cutoff frequency of the low-pass filter is $500 \mathrm{~Hz}$. The deviation between the reference voltage, $V_{r}$, and the feedback voltage, $V_{f b}$, is sent to a PI controller to calculate the value, $V_{a r}$, which is used to position the electrode with respect to the

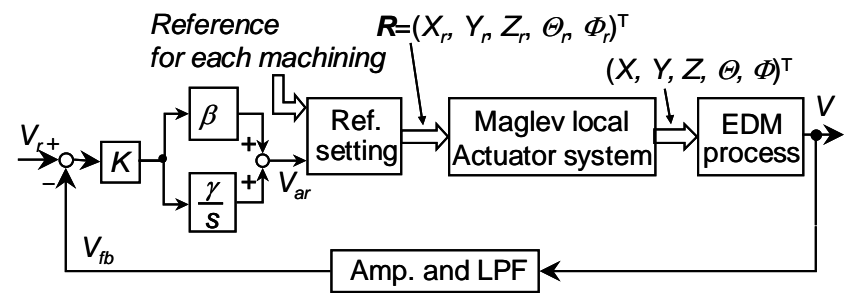

Fig. 2 Block diagram of the EDM control system workpiece. The gain, $K$, is used to adjust the PI controller parameters proportionally. The reference $\boldsymbol{R}$ is the motion path of the electrode.

To give a stable electrical discharge, the reference voltage, $V_{r}$, was set to $2.2 \mathrm{~V}$, and the values of $\mathrm{P}$ and I were set to $4.3 \times 10^{-6}$ and $5.0 \times 10^{-4}$, respectively, by trial and error. Using this EDM system, small holes can be machined in the thrust and radial directions. Furthermore, to adjust the diameter of the small holes, planetary machining was also examined.

\section{ELECTRICAL DISCHARGE MACHINING USING THE MAGLEV LOCAL ACTUATOR 4.1 MACHINING IN THE THRUST DIRECTION}

To machine small holes in the $\mathrm{Z}$ direction, the electrode position in this direction is controlled by the voltage across the gap between the electrode and the workpiece. In this case the $Z_{r}$ of the input reference $\boldsymbol{R}$ of the actuator system was set to $V_{a r}$, and $X_{r}, Y_{r} \Theta_{r}$ and $\Phi_{r}$ were set to zero. That is,

$$
R=\left(\begin{array}{lllll}
X_{r} & Y_{r} & Z_{r} & \Theta_{r} & \Phi_{r}
\end{array}\right)^{T}=\left(\begin{array}{lllll}
0 & 0 & V_{a r} & 0 & 0
\end{array}\right)^{T}
$$

To evaluate the relationship between the machining speed and the bandwidth of the actuator in the machining direction, the bandwidth of the actuator in the $\mathrm{Z}$ direction was experimentally tuned to $5 \mathrm{~Hz}, 25 \mathrm{~Hz}, 50 \mathrm{~Hz}, 75 \mathrm{~Hz}$ and $100 \mathrm{~Hz}$, as shown in Fig. 3(a). The frequency characteristics were designed so that the gain did not exceed $0 \mathrm{~dB}$, thus suppressing overshoot of the electrode. The bandwidths of the actuator were set to $180 \mathrm{~Hz}$ in the $\mathrm{X}$ and $\mathrm{Y}$ directions, and $100 \mathrm{~Hz}$ in the $\Theta$ and $\Phi$ directions. The machining time was set to $300 \mathrm{~s}$. Moreover, to examine the relationship between the machining speed and the control gain of the EDM system, the gain, $K$, was changed from 0.3 to 0.5 .

For comparison, an EDM experiment was also carried out using the conventional electrical discharge machine only. The parameters of the PI controller and the machining conditions were identical to those used for the actuator.

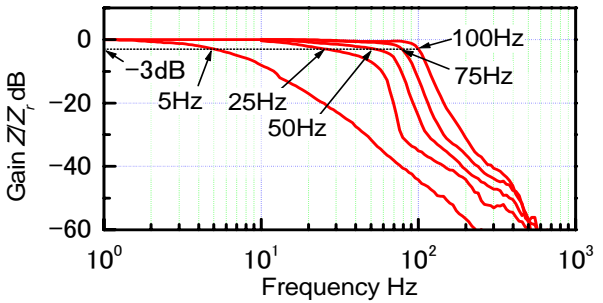

(a) $\mathrm{Z}$ direction

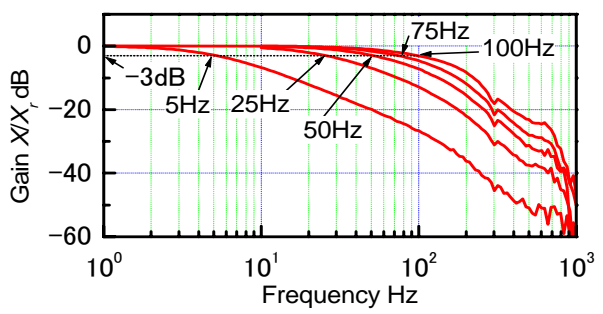

(b) $\mathrm{X}$ direction

Fig. 3 Reference characteristics of the actuator 


\subsection{MACHINING IN THE RADIAL DIRECTION}

The bandwidth of the radial motion (the $\mathrm{X}$ and $\mathrm{Y}$ directions) for the conventional electrical discharge machine shown in Fig. 1 is much lower than that of the $\mathrm{Z}$ direction due to the large mass of the stacked one-DOF tables. The use of the actuator should improve the radial machining speed.

For machining in the radial direction, an L-shaped electrode was attached to the actuator, and the gap between the edge of the electrode and the workpiece in the $\mathrm{X}$ direction was controlled. Therefore, $X_{\mathrm{r}}$ of $\boldsymbol{R}$ was set to $V_{a r}$, and $Y_{r}, Z_{r} \Theta_{r}$ and $\Phi_{r}$ were set to zero, as given by Eq. (2).

$$
R=\left(X_{r} Y_{r} Z_{r} \Theta_{r} \Phi_{r}\right)^{T}=\left(\begin{array}{lllll}
V_{a r} & 0 & 0 & 0 & 0
\end{array}\right)^{T}
$$

As with machining in the thrust direction, the bandwidth of the actuator in the $\mathrm{X}$ direction was experimentally tuned to $5 \mathrm{~Hz}, 25 \mathrm{~Hz}, 50 \mathrm{~Hz}, 75 \mathrm{~Hz}$ and $100 \mathrm{~Hz}$, as shown in Fig. 3(b). The bandwidths of the actuator in the other directions were set to $100 \mathrm{~Hz}$. To realize a stable electrical discharge and increase the machining speed, the control gain, $K$, of the EDM system was varied by trial and error from 0.1 to 0.3 .

The machining time was set to $60 \mathrm{~s}$ which is shorter than that used in thrust machining because the positioning stroke of the actuator in the radial direction is less than that in the $\mathrm{Z}$ direction. Moreover, the EDM experiment was also carried out using conventional EDM only.

\subsection{PLANETARY MACHINING}

The actuator not only can be used for machining small holes, but it can also be used to adjust their diameter. This is done by positioning the electrode to make the gap voltage constant in the $\mathrm{Z}$ direction and driving the electrode in a circular path in the $\mathrm{X}-\mathrm{Y}$ direction. We call this technique planetary machining.

In planetary machining, $\boldsymbol{R}$ is given by Eq. (3).

$$
R=\left(\begin{array}{c}
X_{r} \\
Y_{r} \\
Z_{r} \\
\Theta_{r} \\
\Phi_{r}
\end{array}\right)=\left(\begin{array}{c}
A \cos 2 \pi f t \\
A \sin 2 \pi f t \\
V_{a r} \\
0 \\
0
\end{array}\right)
$$

Where $A$ and $f$ are the radius and frequency of the circular path, respectively. The frequency of the circular path was set to $10 \mathrm{~Hz}$, and the radius was set variously to $10 \mu \mathrm{m}, 20$ $\mu \mathrm{m}, 30 \mu \mathrm{m}$ and $40 \mu \mathrm{m}$, to adjust the diameter of the hole.

The machining time was set to $300 \mathrm{~s}$, and the control gain, $K$, of the EDM system was set to 0.3. Moreover, for a stable electrical discharge, the bandwidths of the actuator were experimentally tuned to $150 \mathrm{~Hz}$ in the $\mathrm{X}$ and $\mathrm{Y}$ directions, $75 \mathrm{~Hz}$ in the $\mathrm{Z}$ direction and $100 \mathrm{~Hz}$ in the $\Theta$ and $\Phi$ directions by trial and error.
Retraction of the electrode from the workpiece in various directions can be chosen in order to avoid short circuiting. Here, the $\mathrm{Z}$ direction was set as the direction of retraction, because the machining algorithm in this direction is the simplest. Before machining holes for these evaluations, several trial EDM processes were carried out to increase the stability of the electrical discharge and the repeatability of the EDM.

\section{MACHINING RESULTS 5.1 MACHINING IN THE THRUST DIRECTION} 5.1.1 MOTION OF THE ELECTRODE

The displacement of the electrode in the $\mathrm{Z}$ direction was measured to evaluate the motion of the electrode during EDM as shown in Fig. 4. The bandwidth of the actuator in the $\mathrm{Z}$ direction was set to $5 \mathrm{~Hz}$ and $100 \mathrm{~Hz}$ and the control gain, $\mathrm{K}$, of the EDM system was set to 0.3 . To maintain the electric discharge the vibration amplitude of the actuator was about ten micrometers and this is within the positioning stroke of the actuator in $5 \mathrm{DOF}$. The amplitudes of vibration do not depend on the bandwidth of the actuator. It can also be seen that, at $100 \mathrm{~Hz}$, the velocity of the electrode in the $\mathrm{Z}$ direction converges as machining progresses since the electrode had tunneled into the workpiece and the whole end surface of the electrode had touched the workpiece. Moreover, for the 5 $\mathrm{Hz}$ bandwidth, vibration of the electrode at a low frequency of $9 \mathrm{~Hz}$ can be seen. This vibration was suppressed by high speed positioning with a bandwidth of $100 \mathrm{~Hz}$.

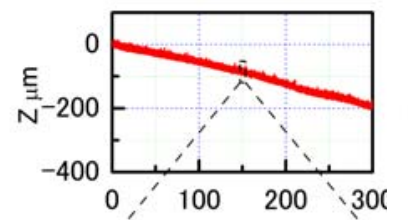

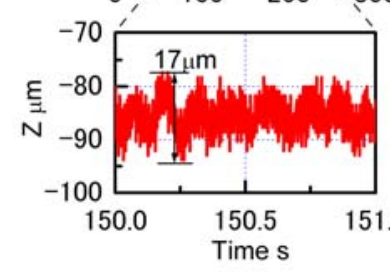

(a) Bandwidth: $5 \mathrm{~Hz}$

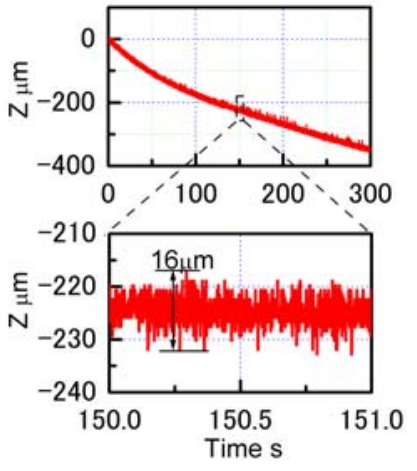

(b) Bandwidth: $100 \mathrm{~Hz}$
Fig. 4. Displacements of the electrode in the $\mathrm{Z}$ direction during EDM

\subsubsection{PROFILES OF THE MACHINED HOLES}

Profiles of the machined holes were measured with a confocal microscope (HD100D, Lasertec Corp., 1.6 $\mathrm{mm} \times 1.6 \mathrm{~mm}$ region with $900 \times 900$ pixels, $0.01 \mu \mathrm{m}$ resolution in terms of height). The top surfaces and cross-sectional profiles of the holes are shown in Fig. 5. The depth and diameter of the hole machined with a bandwidth of $5 \mathrm{~Hz}$ are $0.165 \mathrm{~mm}$ and $1.038 \mathrm{~mm}$, respectively. The depth of the hole machined with a bandwidth of $100 \mathrm{~Hz}$ increased by 71.5\%, whereas the diameter was almost the same. Moreover, from the deviation between the displacement of the electrode and the depth of the hole, the electrode wear can be 


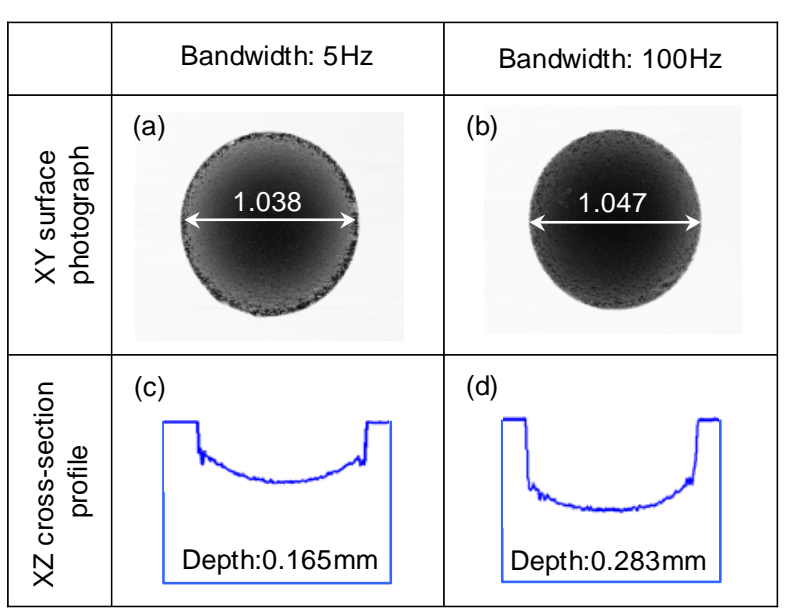

Fig. 5. Machined holes in the $\mathrm{Z}$ direction (Gain $K=0.3$ )

calculated approximately. This was found to be $27 \mu \mathrm{m}$ for $5 \mathrm{~Hz}$ and $66 \mu \mathrm{m}$ for $100 \mathrm{~Hz}$. As for the wear rate of the electrode to the depth of the hole, the high-speed actuator is greater.

\subsubsection{MEASUREMENT OF THE AVERAGE GAP VOLTAGE}

During EDM, the feedback voltage was measured with a data recorder (EZ7510, NF Corp., resolution, 16bit, sampling frequency of $10 \mathrm{kHz}$ ), as shown in Fig. 6 . Although the signal after the filter does not show open and short circuits in the strict meaning of these terms, we consider that it is effective in evaluating the average electric discharge condition. Here, a feedback voltage, $V_{f b}$, of $0 \mathrm{~V}$ implies that the electrical discharge circuit is shorted. $V_{f b}$, of $3.6 \mathrm{~V}$ implies that the electrical discharge circuit is open. i.e., the gap voltage is equal to the power supply voltage $(120 \mathrm{~V})$ at this time. Comparing Fig. 6(a) with Fig. 6(b), it can be seen that the rate of incidence of short and open circuits decreases, and the response of the electrode to short and open circuits is enhanced as the bandwidth of the actuator is increased.

\subsubsection{MACHINING SPEED}

For each EDM experiment, several holes were machined under the same conditions and five holes except those holes influenced by large abnormal electrical discharges were used for calculating the average machining speed. The machining speed is defined as the ratio of the average depth of five holes to machining time. The relationships between average machining speed, the bandwidth of the actuator and the control gain of the EDM system are shown in Fig. 7. Here, the gain, $K$, was varied from 0.3 to 0.5 . The electrical discharge becomes unstable when the gain exceeds 0.5. The average machining speed using the actuator with a bandwidth of more than $25 \mathrm{~Hz}$ improved compared to using conventional EDM only. From this data, the bandwidth of the conventional electrical discharge machine in the $\mathrm{Z}$ direction was estimated to be $25 \mathrm{~Hz}$ or less. Moreover, as the bandwidth of the actuator and the control gain of the EDM system were increased, the average machining speed also increased.

We assume that a stable electrical discharge takes place when the average gap voltage is within $10 \%$ to $90 \%$ of the open-circuit voltage. The total electrical discharge time was calculated approximately using the measured feedback voltage. Defining the electrical discharge probability as the ratio of total electrical discharge time to machining time, the electrical discharge probability as a simple index of stable electrical discharge is shown in Fig. 8. As for the average machining speed, the electrical discharge probability using the actuator with a bandwidth of more than $25 \mathrm{~Hz}$ also improves compared to using conventional EDM only. Furthermore, as the bandwidth of the actuator is increased, the electrical discharge probability increases. However, at the same bandwidth, as the control gain of the EDM system increases, the electrical discharge probability does not increase. We intend to examine this phenomenon in the future work.

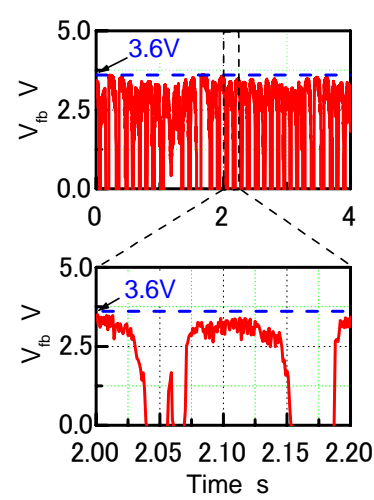

(a) Bandwidth: $5 \mathrm{~Hz}$

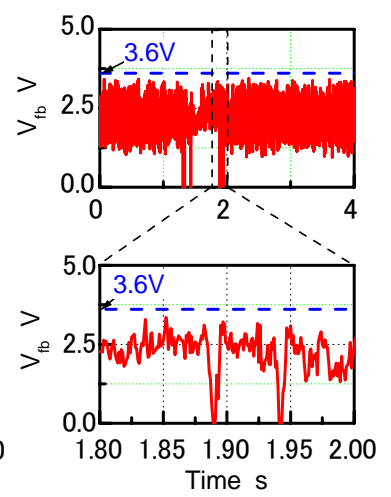

(b) Bandwidth: $100 \mathrm{~Hz}$
Fig. 6. Feedback voltage $\left(V_{f b}\right)$ in $\mathrm{Z}$ direction machining

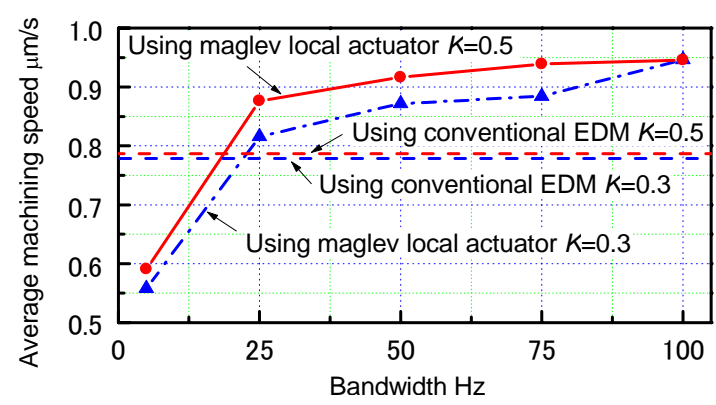

Fig. 7. Relationships between the average machining speed, the bandwidth of the actuator in the $\mathrm{Z}$ direction and the control gain, $K$, of the EDM system

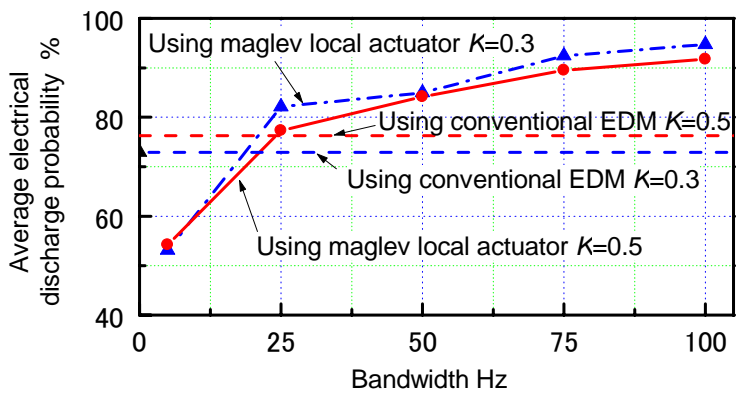

Fig. 8. Average electrical discharge probability in $\mathrm{Z}$ direction machining 


\subsection{MACHINING IN THE RADIAL DIRECTION}

The relationships between machining speed, the bandwidth of the actuator and the control gain, $K$, of the EDM system were also examined for machining in the radial direction. These are shown in Fig. 9. The tendency of the machining performance is the same as that for machining in the thrust direction. Therefore, to realize high speed machining, it is necessary to select a large bandwidth for the actuator and a suitable control gain for the EDM system.

Furthermore, by increasing the bandwidth of the actuator, the average machining speed is improved compared to conventional EDM only. Moreover, when using conventional EDM only, the machining speed cannot be increased by increasing the control gain, $\mathrm{K}$. From this phenomenon, it can be seen that if the response of the actuator is insufficient, the machining speed cannot be improved even if the control gain of the EDM system is increased.

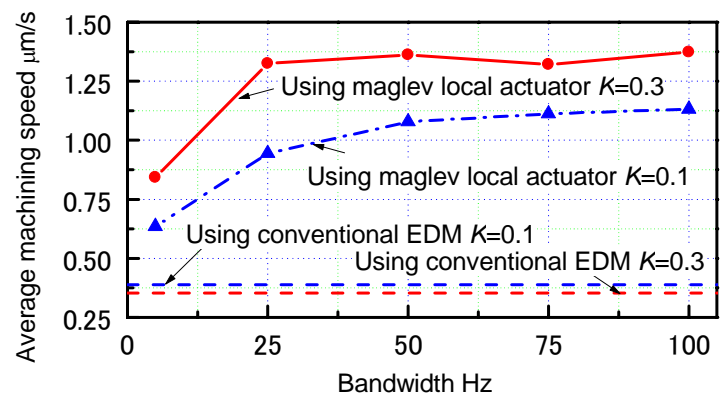

Fig. 9. Relationships between the average machining speed, the bandwidth of the actuator in the $\mathrm{X}$ direction and the control gain, $K$, of the EDM system

\subsection{PLANETARY MACHINING}

In order to adjust the diameters of small holes, planetary machining was attempted. The upper surfaces of the holes and the motion paths of the electrode in the $\mathrm{X}, \mathrm{Y} \Theta$ and $\Phi$ directions are shown in Fig. 10. Setting the diameter of the circular path to $0 \mu \mathrm{m}$, the diameters of the hole were $1.043 \mathrm{~mm}$ and $1.045 \mathrm{~mm}$, in the $\mathrm{X}$ and $\mathrm{Y}$ directions, respectively. Increasing the diameter of the circular path to $20 \mu \mathrm{m}$, the diameters of the hole became $1.063 \mathrm{~mm}$ and $1.064 \mathrm{~mm}$. It can be seen that the diameter of the hole was expanded by approximately $20 \mu \mathrm{m}$, identical to the diameter of the circular path.

Fig. 11 shows the relationship between the increments in the diameters of five holes machined under the same conditions and the diameter of the circular path. For circular path diameters of less than $20 \mu \mathrm{m}$, the diameter of the machined hole could be adjusted in proportion to the diameter of the circular path. However, above $20 \mu \mathrm{m}$, the machined profiles of the holes became distorted, and the variation in the diameter of the machined holes became larger. For each planetary machining process, the motion of the electrode was measured and it was confirmed that the trajectory was exactly as desired. Furthermore, the cylindricality of the electrode was judged to be high because the cylindricality of the machined hole was high for a circular path of $0 \mu \mathrm{m}$ diameter. Therefore, we consider that the distortion and variation in the holes was due to an unstable electrical discharge.

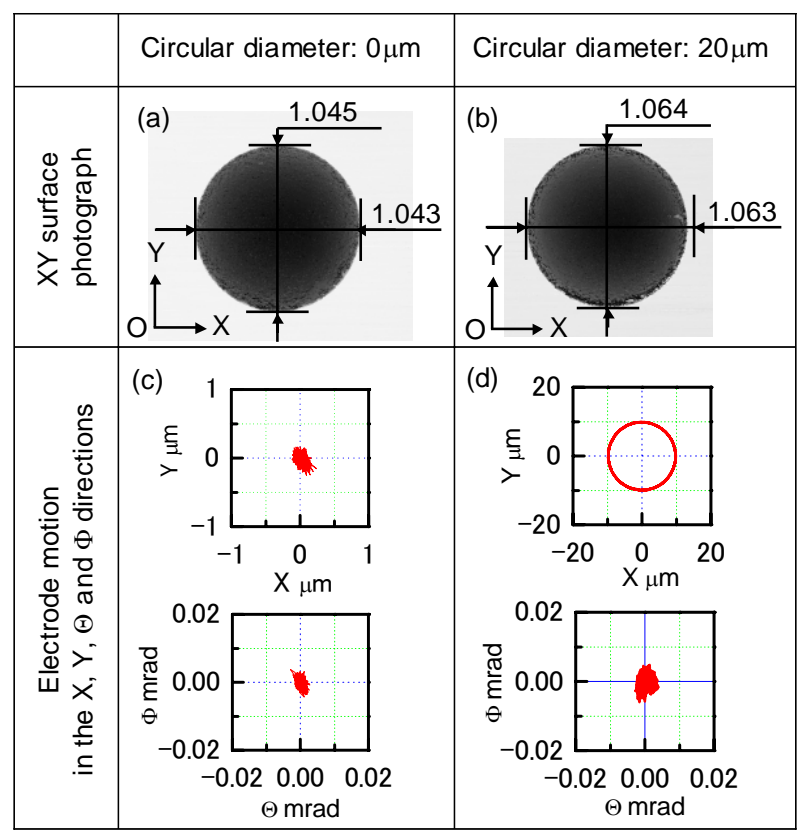

Fig. 10. Planetary machining

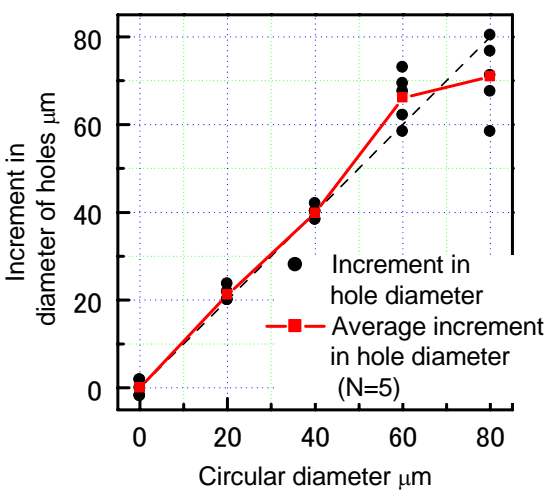

(a) In $\mathrm{X}$ direction

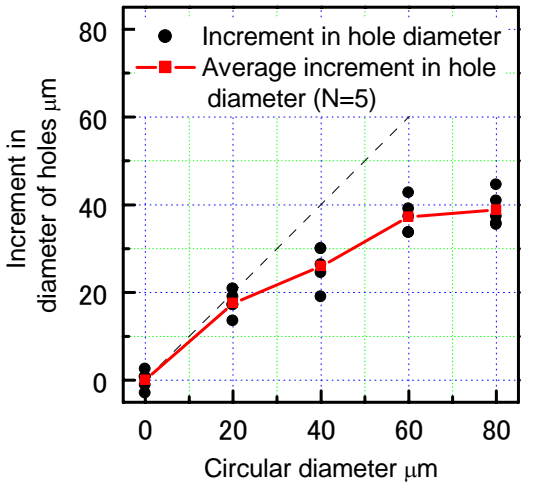

(b) In Y direction

Fig. 11. Relationship between the increase in the diameter of holes and the diameter of the circular path of the electrode 


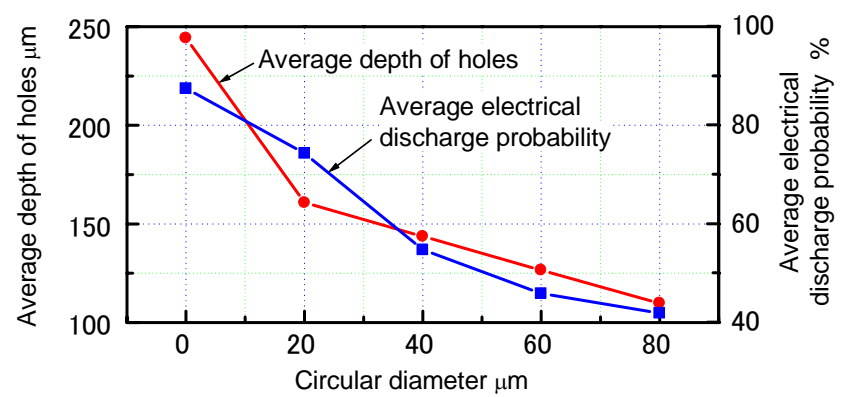

Fig. 12. Average depth of the holes and average electrical discharge probability in planetary machining

The average depth of the holes and the electrical discharge probability for different diameter circular paths are shown in Fig. 12. As the diameter of the circular path becomes large, the average depth of the holes becomes shallow and the electrical discharge probability decreases. As the diameter of the circular path increases, the electrical discharge in planetary machining becomes unstable in the $\mathrm{Z}$ direction. Thus, for planetary machining, retraction limited to the $\mathrm{Z}$ direction is insufficient to avoid short-circuits in the radial and thrust directions. In future, we will consider a suitable method for retracting the electrode to improve the machining speed and adjusting the diameter of small machined holes to larger values.

\section{CONCLUSIONS}

This paper discusses the relationships between machining speed, the bandwidth of a maglev local actuator and the control gain of an EDM system. The machining speed can be increased as the bandwidth of the actuator and the control gain of the EDM system are increased. Moreover, by planetary motion of the electrode, the diameter of the machined hole could be adjusted by up to about an additional ten micrometers in radius.

In future work, we will discuss a suitable method for retracting the electrode to increase the diameter of small machined holes to larger sizes, and we will improve the actuator to make it more compact and improve the stability of the rotational motion

\section{ACKNOWLEDGMENT}

This research was supported in part by Grants-in-Aid for Scientific Research (KAKENHI) from the Japan Society for Promotion of Science. The authors gratefully acknowledge the contributions of Mr. H. Endo and Mr. H. Morita for their support concerning the experiments.

\section{REFERENCE}

[1] Kunieda, M., Lauwers, B., Rajurkar, K. P. and Schumacher, B. M., 2005, Advancing EDM through fundamental Insight into the Process, Annals of the CIRP, Vol. 54, No. 2, pp. 599-622.

[2] Ho, K. H. and Newman, S. T., 2003, State of the art electrical discharge machining (EDM), International Journal of Machine Tools and Manufacture, Vol. 43, No. 13, pp. 1287-1300.

[3] Masuzawa, T., 2000, State of Art of Micromachining, Annals of the CIRP, Vol. 49, No. 2, pp. 473-488.

[4] Imai, Y., Satake, A., Taneda, A. and Kobayashi, K., 1996, Improvement of EDM machining speed by using high frequency response actuator, International Journal Electrical Machining, No. 1, pp. 21-26.

[5] Masuzawa, T., Tanaka, K. and Fujino, M., 1978, Study on the high speed machining by EDM using a moving coil head type feed control, Proceedings of the 19th International MTDR Conference, pp. 543-549.

[6] Imai, T., Nakagawa, T., Miyake, H., Hidai, H. and Tokura, H., 2004, Local actuator module for highly accurate micro-EDM, Journal of Materials Processing Technology, Vol. 149, No. 3, pp. 328-333.

[7] Zhang, X., Shinshi, T., Endo, H., Kajiwara, G., Shimokohbe, A., Imai, Y., Miyake, H. and Nakagawa, T., 2006, A 5-DOF controlled maglev actuator for electrical discharge machining, Proceedings of the $2^{\text {nd }}$ International Conference on Positioning Technology, pp. 22-23.

[8] Zhang, X., Shinshi, T., Kajiwara, G., Shimokohbe, A., Imai, Y., Miyake, H. and Nakagawa, T., 2007, 5-DOF Controlled Maglev Local Actuator and its Application to Electrical Discharge Machining, Precision Engineering, in submission. 